\title{
Synthesis of Low-Temperature Stable Polymers. I. Chain-Extended Poly(tetrahydrofuran-urethane)
}

\author{
G.'P. Rajendran, V. MahadeVan, and M. SRinivasan \\ Department of Chemistry, Indian Institute of Technology, \\ Madras-600 036, India.
}

(Received April 10, 1980)

\begin{abstract}
Tetrahydrofuran was polymerised with boron trifuoride etherate $\left(\mathrm{BF}_{3} \cdot \mathrm{Et}_{2} \mathrm{O}\right)$ and terminated with hydrobromic acid to give the bromide-terminated prepolymer, which, on further reaction with ketal derivative of glycerol and subsequent hydrolysis, gave tetrahydroxylterminated polytetrahydrofuran. The prepolymer was chain-extended with tolylenediisocyanate and hexamethylenediisocyanate in six different solvents to give cross-linked polyurethane. These polymers were characterised by infrared, viscosity and thermogravimetric analysis. The glasstransition temperature, the tensile strength at break, and elongation were also determined.

KEY WORDS Poly(tetrahydrofuran) / Chain Extension / Polyurethane / Tolylenediisocyanate / Hexamethylenediisocyanate / Glass-Transition Temperature / Tensile Strength /
\end{abstract}

The diisocyanate polymer chain-extension technique has been utilised in many fields of polymer technology to produce materials such as foams, coatings, castable elastomers, ${ }^{1}$ and cryogenic adhesives. ${ }^{2}$ The coreactants that have been used are hydroxyl-terminated polyesters, polyethers, and some naturally occurring products such as castor oil. For many reasons, such as mix-fluidity and improved low-temperature flexibility, polyethers are preferred in urethane technology. The three principal types of polyethers used in work up to the present are poly(ethylene glycol)s, poly(propylene glycol)s and poly(tetrahydrofuran glycol)s, and the glycols obtained from the copolymerization of cyclic ethers. ${ }^{3}$ The tetrahydrofuran(THF)-based polyurethanes (PU) were found to have the best physical and low-temperature properties. ${ }^{4}$

Cross-linking was normally introduced into the urethane-extended polymers through the use of intermediates possessing more than two functional groups or through secondary reactions of the isocyanate group with - $\mathrm{NH}$ - groups derived from the primary reactions of the isocyanate group. The polyfunctionality could also be introduced in the glycol intermediates by polymerising the cyclic ethers with initiators having more than two func- tional groups. ${ }^{5,6}$ The introduction of cross-linking into the polymers results in a polymer having a low glass-transition temperature, a decrease in elongation; the cross-linking has an insignificant effect on tensile strength.

\section{EXPERIMENTAL}

\section{Materials and Methods}

Boron trifluoride etherate (Fluka AG), tolylenediisocyanate (TDI) (2:4 isomer Reidel), and hexamethylenediisocyanate (HMDI) (Fluka AG) were all distilled prior to use in the experiments. The tetrahydrofuran, triethylamine, and dioxane (AR samples) were purified as usual. ${ }^{7}$ The polymerisation solvents, acetonitrile, methyl ethyl ketone (MEK), methyl isobutyl ketone (MIBK), and dichloromethane in analar qualities were dried by being kept overnight with phosphorous pentoxide, filtered, and fractionated in the reported boiling ranges. The ketal derivative of glycerol was prepared from dry glycerol and acetone with $p$ toluenesulfonic acid as catalyst. ${ }^{8}$

The infrared spectra of polymers were taken by a Perkin-Elmer 257 spectrometer $(\mathrm{KBr}$ pellets and Nujol mulls). The intrinsic-viscosity measurements 
were made with an Ubbelhode viscometer. The Mark-Houwink constants reported by Kurata et $a l .{ }^{9}$ were used for calculating molecular weights. The thermogravimetric analysis were performed with a Stanton thermobalance at a heating rate of $8^{\circ} \mathrm{C} \min ^{-1}$ in air. The glass-transition temperatures were measured by the dilatometric technique. ${ }^{10}$ The instrument used for tensile strength at the break and elongation was designed and assembled locally; the temperature of the system was maintained at $-60 \pm 1^{\circ} \mathrm{C}$ by a regulated flow of liquid nitrogen.

\section{Prepolymer Preparation}

Tetrahydrofuran can be polymerised by a variety of initiators. ${ }^{11} \mathrm{BF}_{3} \cdot \mathrm{Et}_{2} \mathrm{O}$ was used as the initiator for polymerisation. ${ }^{12}$ Dry THF $(20 \mathrm{ml})$ and $\mathrm{BF}_{3} \cdot \mathrm{Et}_{2} \mathrm{O}(3 \mathrm{ml})$ were taken in a sealed ampule tube of $50 \mathrm{ml}$ capacity and allowed to polymerise at $-15^{\circ} \mathrm{C}$. After two hours, polymerisation was terminated with $48 \%$ hydrobromic acid $(3 \mathrm{ml})$. The polymer was precipitated by agitation with water, filtered, washed with water several times, and dried in vacuum for three days. The net conversion of THF to bromine-terminated poly(THF) was 6 to

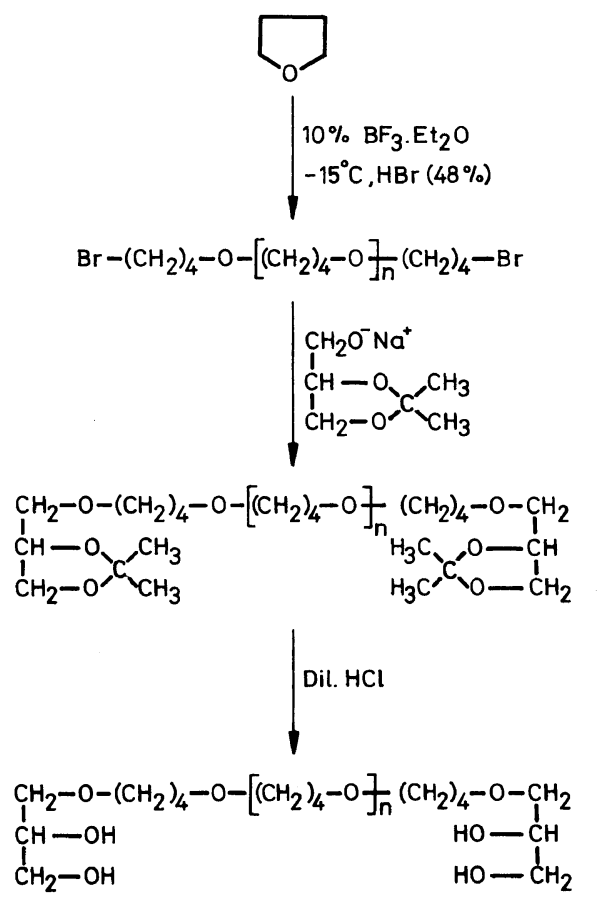

Scheme 1. Schematic representation of preparing tetrahydroxyl-terminated polytetrahydrofuran.

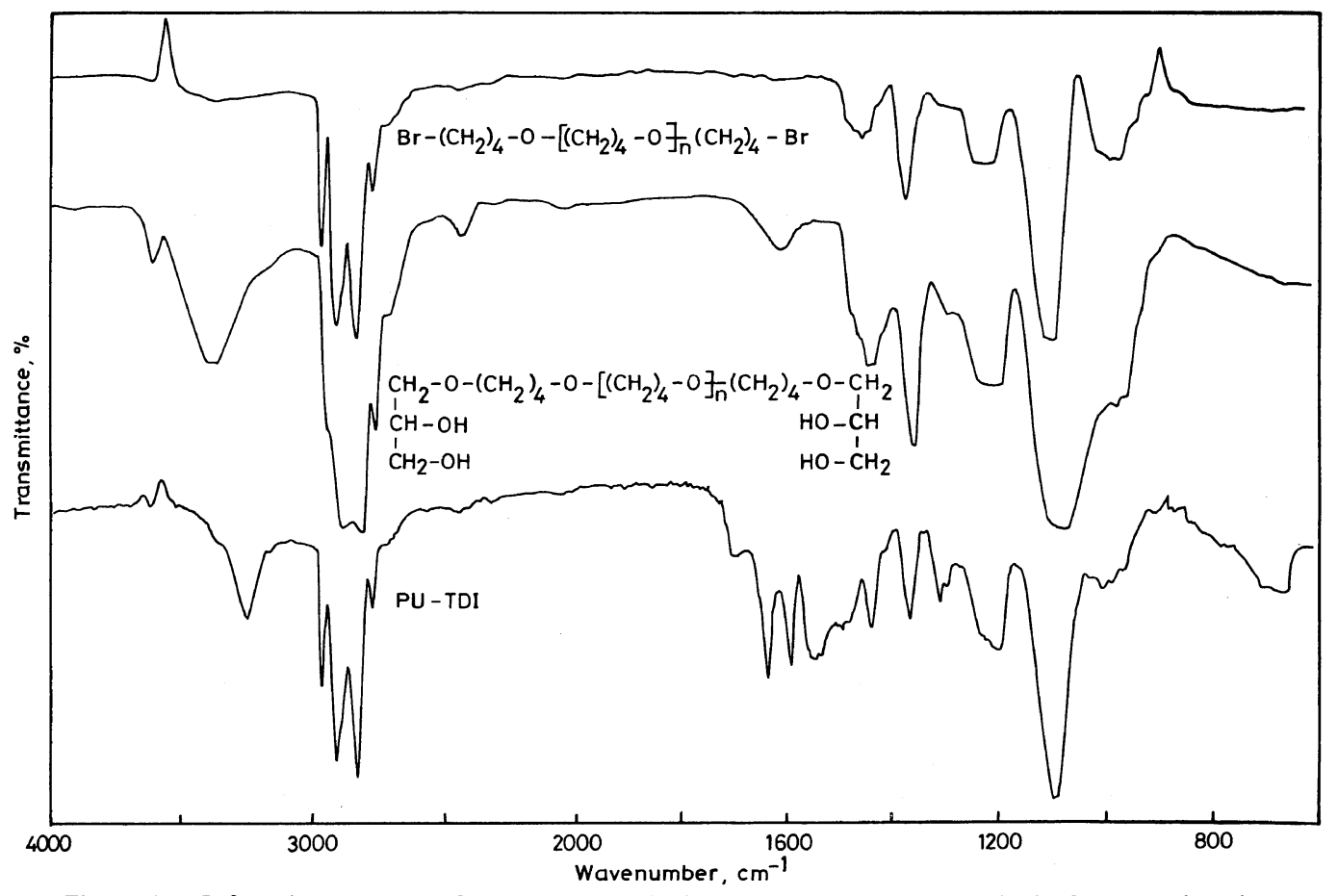

Figure 1. Infrared spectrum of Bromo-, tetrahydroxy-terminated polytetrahydrofuran and polyurethane. 
$7 \%$ only. The end bromide group was identified by infrared (IR) and qualitative elemental analysis (presence of bromine). The net bromine content was estimated quantitatively ${ }^{13}$ to 1.91 equivalents $\mathrm{mol}^{-1}$. The bromide was treated with the sodium salt of the ketal derivative of glycerol in a dry dioxane medium and then subjected to hydrolysis with dilute $(10 \%)$ hydrochloric acid to give tetrahydroxyl-terminated polytetrahydrofuran (refer to Scheme, for IR, Figure 1). The yield was quantitative for the most part in the above two steps. The prepolymer was selectively precipitated to give an appropriate molecular weight 10210 100) from toluene by the addition of methanol resulting in low-molecular-weight prepolymers (yield $65-70 \%$ ). The prepolymer was filtered, washed with methanol, and dried in vacuum for three days at room temperature. The prepolymer was also characterised by infrared and qualitative elemental analysis (absence of bromine). The hydroxyl numbers were determined according to the procedure of Sherwood et al. ${ }^{14}$ (refer to Table II). The molecular weight of the prepolymer was found to be $(10210 \pm 100)$ from the intrinsic-viscosity value in benzene. Prepolymers having different molecular weights were prepared by varying the amounts of initiator and the amount of time for polymerisation. The prepolymers were waxy solids which melted below $50^{\circ} \mathrm{C}$.

\section{Chain Extension with Diisocyanates}

Chain extension of prepolymers was carried out in a round bottom flask equipped with a mechanical stirrer, a reflux condenser protected by a guard tube, a dropping funnel, and a nitrogen inlet. ${ }^{15}$ To a solution containing prepolymer (molecular weight, 10210) with a few drops of triethylamine as catalyst, a solution containing the appropriate diisocyanate ( 2 equivalents viz., equal molar concentration of $\mathrm{OH}$ and $\mathrm{NCO}$ groups) was added dropwise at $0-10^{\circ} \mathrm{C}$ with effective stirring. Following this, the temperature of the bath was slowly increased to $70^{\circ} \mathrm{C}$ and then maintained at $70^{\circ} \mathrm{C}$ for five hours. A small amount of dry methanol was added to the solution to convert the free - $\mathrm{NCO}$ end groups to urethane groups before precipitation (to avoid the formation of urea with water during precipitation). The polymer was precipitated in water. (In the case of solvents like dichloromethane and MIBK, the solvent was evaporated under reduced pressure, the viscous mass was dissolved in dimethylformamide (DMF) and then precipitated in water). Though gelation was expected to occur when equal molar con-

Table I. Spectral characteristic, molecular weight(s) and polyurethane yield (prepolymer molecular weight, 10210)

\begin{tabular}{|c|c|c|c|c|c|}
\hline \multirow{2}{*}{ Solvent } & \multirow{2}{*}{$\begin{array}{l}\mathrm{C}=\mathrm{O} \\
\mathrm{cm}^{-1}\end{array}$} & \multirow{2}{*}{$\frac{-\mathrm{NH}-}{\mathrm{cm}^{-1}}$} & \multirow{2}{*}{$\eta_{\text {int }}^{\mathrm{a}}$} & \multirow{2}{*}{$\begin{array}{c}\text { Molecular weight } \\
\mathrm{M} \times 10^{-4}\end{array}$} & \multirow{2}{*}{$\frac{\text { Yield }}{\%}$} \\
\hline & & & & & \\
\hline \multicolumn{6}{|c|}{ TDI-based polyurethanes } \\
\hline THF & 1640 & 3240 & 0.271 & 10.96 & 84 \\
\hline Dioxane & 1650 & 3250 & 0.206 & 5.62 & 78 \\
\hline MEK & 1650 & 3230 & 0.180 & 4.06 & 73 \\
\hline Acetonitrile & 1660 & 3240 & 0.170 & 3.51 & 71 \\
\hline MIBK & 1645 & 3240 & 0.176 & 3.85 & 68 \\
\hline Dichloromethane & 1645 & 3260 & 0.166 & 3.33 & 63 \\
\hline \multicolumn{6}{|c|}{ HMDI-based polyurethanes } \\
\hline THF & 1670 & 3240 & 0.283 & 12.19 & 86 \\
\hline Dioxane & 1660 & 3250 & 0.206 & 5.62 & 73 \\
\hline MEK & 1650 & 3230 & 0.217 & 6.39 & 69 \\
\hline Acetonitrile & 1640 & 3240 & 0.178 & 3.94 & 72 \\
\hline MIBK & 1645 & 3240 & 0.175 & 3.78 & 63 \\
\hline Dichloromethane & 1650 & 3260 & 0.163 & 3.18 & 62 \\
\hline
\end{tabular}

${ }^{\text {a }}$ Intrinsic viscosities were measured in dimethylformamide at $30^{\circ} \mathrm{C}$ and at $0.1 \mathrm{~g} \mathrm{dl}^{-1}$ concentration. 
centrations of $\mathrm{OH}$ and $\mathrm{NCO}$ groups were employed, no gelation took place but precipitation occurred when dichloromethane and methyl isobutyl ketone were used as the polymerisation solvents. The polymer was filtered, washed with benzene and methanol, and dried in a vacuum at room temperature for three days. The polymer yields were each around $60-80 \%$.

\section{RESULTS AND DISCUSSION}

The IR spectra of the polymers showed a characteristic absorption at $1650 \pm 10 \mathrm{~cm}^{-1}$ and $3240 \pm 10 \mathrm{~cm}^{-1}$ due to the stretching frequencies of the $-\mathrm{C}=\mathrm{O}$ and $-\mathrm{NH}-$ groups, respectively and a strong peak at $1100 \mathrm{~cm}^{-1}$ due to the $\mathrm{C}-\mathrm{O}-\mathrm{C}$ group stretching. The intrinsic-viscosity values were measured in dimethylformamide at $30^{\circ} \mathrm{C}$. These values are presented in Table I.

From the intrinsic-viscosity values obtained for the various prepolymers determined in dimethylformamide and benzene as solvents, the molecular weight of the polyurethane was calculated as per the literature method. ${ }^{16}$ This calculated molecular weight gives an idea of the extent of the polymerisation and hence an idea of the chain extensions in the various solvents employed as polymerisation media. The details furnished in Table I in this connection clearly indicate THF to be the most ideal solvent for polymerisation since chain extension takes place in this solvent more than in others. The chain extension carried out in solvents such as dichloromethane and methyl isobutyl ketone result- ed in the precipitation of the polymers. This was due to the poor solubility of the polymers in the above solvents, thus lowering the degree of chain extension. All polymers were found to be more soluble in THF in comparison to other solvents such as methyl ethyl ketone, acetonitrile, and dioxane. Hence, the higher degree of chain extension in

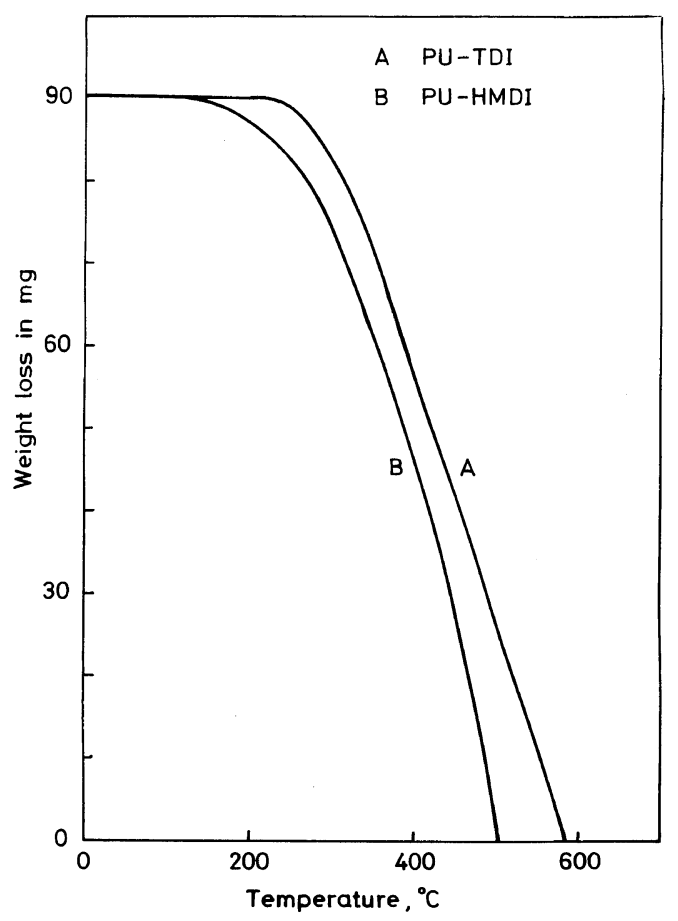

Figure 2. Thermal stabilities of polyurethanes.

Table II. Influence of prepolymer molecular weight on glass-transition temperatures

\begin{tabular}{|c|c|c|c|c|c|c|c|}
\hline \multirow{2}{*}{$\begin{array}{l}\text { Prepolymer } \\
\text { molecular } \\
\text { weight }\end{array}$} & \multicolumn{2}{|c|}{ Hydroxyl number } & \multirow{2}{*}{ Diisocyanate } & \multirow{2}{*}{$\begin{array}{l}\text { Density } \\
\mathrm{g} \mathrm{cm}^{-3}\end{array}$} & \multirow{2}{*}{$\begin{array}{r}T_{\mathrm{g}} \\
{ }^{\circ} \mathrm{C}\end{array}$} & \multirow{2}{*}{$\eta_{\mathrm{int}}^{\mathrm{b}}$} & \multirow{2}{*}{$\begin{array}{c}\text { Molecular weight } \\
\qquad \mathrm{M} \times 10^{-4}\end{array}$} \\
\hline & Calcd & Obsd & & & & & \\
\hline 10210 & 21.9 & 21.3 & TDI & 0.965 & -11 & 0.271 & 10.96 \\
\hline 14510 & 15.5 & 15.4 & TDI & 1.078 & -18 & 0.354 & 20.89 \\
\hline 22620 & 9.9 & 9.6 & TDI & 1.110 & -36 & 0.392 & 26.79 \\
\hline 10210 & 21.9 & 21.3 & HMDI & 0.960 & -13 & 0.283 & 12.19 \\
\hline 14510 & 15.5 & 15.4 & HMDI & 0.980 & -28 & 0.341 & 19.10 \\
\hline 22620 & 9.9 & 9.6 & HMDI & 1.041 & -41 & 0.379 & 24.77 \\
\hline
\end{tabular}

a The term hydroxyl number defines the number of milligrams of potassium hydroxide equivalent to the hydroxyl content of one gram of the polymer.

b Intrinsic viscosities were measured in diemthylformamide at $30^{\circ} \mathrm{C}$ and at $0.1 \mathrm{~g} \mathrm{dl}^{-1}$ concentration. 
THF as the chain-extension medium can be attributed to the higher solubility of the polymers. Hence further study was carried out on THF as a polymerisation solvent.

Determination of hydroxyl numbers of the final polymers was very low (PU-TDI 1.7 and PU-HMDI 0.8 ) indicating that the polymer is cross-linked. All polymers were soluble in DMF, dimethylacetamide (DMAc), dimethyl sulfoxide (DMSO), THF, and in dioxane. A thermogravimetric analysis of the TDI-based polyurethanes (prepolymer molecular weight, 10210) showed that these polymers were stable up to $240^{\circ} \mathrm{C}$ in air but started decomposing above this temperature with total decomposition occurring at $580^{\circ} \mathrm{C}$. However, HMDI-based polyurethane were stable upto $170^{\circ} \mathrm{C}$ in air and a total weight loss was found to occur at $510^{\circ} \mathrm{C}$ (Figure 2).

The glass-transition tempratures were found to be $-11^{\circ} \mathrm{C}$ and $-18^{\circ} \mathrm{C}$ from dilatometric studies on the TDI- and HMDI-based polyurethanes with prepolymer molecular weight, 10210. The $T_{\mathrm{g}}$ of the polymers were found to decrease and the densities were found to increase with an increase in the molecular weight of each prepolymer, as shown in Table II.

The tensile strength of the polymers (with prepolymer molecular weight, 10210) at the break and the percentage of elongation were measured at room temperature and at $-60^{\circ} \mathrm{C}$, using fibers of uniform thickness $(1 \mathrm{~mm})$. The fiber obtained from HMDI polymer was brittle at room temperature.

\begin{tabular}{|c|c|c|c|}
\hline \multirow{3}{*}{ Polymer } & Temp & \multirow{3}{*}{$\begin{array}{c}\begin{array}{c}\text { Tensile } \\
\text { strength }\end{array} \\
\mathrm{kg} \mathrm{cm}^{-2}\end{array}$} & Elongation \\
\hline & \multirow{2}{*}{${ }^{\circ} \mathrm{C}$} & & \multirow{2}{*}{$\%$} \\
\hline & & & \\
\hline \multirow[t]{2}{*}{ RU-TDI } & Room temp & 63.0 & 295 \\
\hline & -60 & 92.3 & 220 \\
\hline PU-HMDI & -60 & 36.9 & 185 \\
\hline
\end{tabular}

Acknowledgement. The authors should like to express their appreciation for the financial assistance provided by the Indian Space Research Organisation, India.

\section{REFERENCES}

1. "Advances in Polyurethane Technology," J. N. Buist and H. Gudgeon, Ed., Elsevier Publishing Company, London, 1968.

2. M. B. Smith and S. E. Susman, "Advances in Cryogenic Engineering," Vol. 8, Timmerhaus, Ed., Plenum Press, New York, N.Y., 1962, pp 300-305.

3. W. J. Murbach and A. Adicoff, Ind. Eng. Chem., 52, 572 (1960).

4. R. B. Gosnell and H. H. Levine, presented at the Symposium on Polymer in Space Research, Pasadena, California, July 15-17, 1968.

5. C. C. Price (to University of Notre Dame), U.S. Patent, 2866774 (Dec. 30, 1958); Chem. Abstr., 53, $6667 i$.

6. T. L. Smith and A. B. Magnusson, J. Polym. Sci., 42, 391 (1960).

7. A. I. Vogel, "Textbook of Practical Organic Chemistry," Longaman, Green and Co. Ltd., London, 1978.

8. J. R. Irvine, J. L. A. McDonalds, and C. W. Sontar, J. Chem. Soc., 107, 337 (1915).

9. M. Kurata, H. Utiyama, and K. Kamada, Makromol. Chem., 88, 281 (1965).

10. J. D. Ferry and G. S. Parks, J. Chem. Phys., 4, 70 (1936).

11. P. Dreyfuss and M. P. Dreyfuss, Adv. Polym. Sci., 4, 528 (1967), Springer-Verlag, Berlin-Heidelberg-New York, N.Y., 1965-1967.

12. R. C. Burrows and C. F. Crowe, J. Appl. Polym. Sci., 6, 465 (1962).

13. "ASTM Standards Part-9, D1303-55," The American Society for Testing and Materials, Philadelphia, 517, 1958.

14. "Analytical Chemistry of Polyurethanes," Vol. XVI, D. J. David and H. B. Staley, Ed., Wiley Intersciences, New York, N.Y., London, Part-III, p 289.

15. G. Ansuino, A. Pirro, O. Rossi, and L. Polo Friz, J. Polym. Sci., Polym. Chem. Ed., 13, 1657 (1975).

16. A. I. Goldberg, W. P. Hobenstein, and H. Mark, J. Polym. Sci., 2, 503 (1947). 